NBER WORKING PAPER SERIES

GROWTH WITHOUT SCALE EFFECTS

Alwyn Young

Working Paper No. 5211

NATIONAL BUREAU OF ECONOMIC RESEARCH

1050 Massachusetts Avenue

Cambridge, MA 02138

August 1995

This research was supported by the Canadian Institute for Advanced Research. I am grateful for the comments of Elhanan Helpman, Chad Jones, Paul Romer and seminar participants at Boston University, the CIAR, Columbia University, and the NBER's productivity lunch. This paper is part of NBER's research program in Growth. Any opinions expressed are those of the author and not those of the National Bureau of Economic Research.

(C) 1995 by Alwyn Young. All rights reserved. Short sections of text, not to exceed two paragraphs, may be quoted without explicit permission provided that full credit, including (C) notice, is given to the source. 


\title{
GROWTH WITHOUT SCALE EFFECTS
}

\begin{abstract}
An increase in the size (scale) of an economy increases the total quantity of rents that can be captured by successful innovators which, in equilibrium, should lead to a rise in innovative activity. Conventional wisdom and the theoretical predictions of models of endogenous innovation suggest that this increased research effort should lead to more rapid growth. As noted by Jones [1993], this prediction is at odds with the postwar experience of the OECD, where the growth of the market has indeed led to an increased R\&D effort which, however, has been translated into stagnant or declining growth rates. Drawing upon the remarkable insights of the museum curator S.C. Gilfillan [1935], this paper modifies models of endogenous innovation to allow for the possibility that a rise in the profitability of innovative activity could lead to an increased variety of differentiated solutions to similar problems. An increased variety of technologies (e.g. an increase in the number and types of contraceptives) will increase the level of utility of the average consumer. If, however, continued improvement of this increased variety of technologies requires increased research input, a rise in the scale of the market could raise the equilibrium quantity of R\&D, without increasing the economy's growth rate. Furthermore, increased product variety, brought about by increases in market size, might reduce the returns to improving product quality, paradoxically lowering an economy's growth rate while increasing the total resources devoted to $R \& D$.
\end{abstract}

\author{
Alwyn Young \\ Department of Economics \\ Boston University \\ 270 Bay State Road \\ Boston, MA 02215 \\ and NBER
}




\section{Introduction}

Writing in 1935, summarizing the "Social Principles of Invention" gleaned from his monumental study of technological change in merchant shipping, the museum curator and sociologist S.C. Gilfillan [1935a,b] anticipated one of the central implications of modern growth theory: that larger economies, which devote greater resources to innovation, should grow faster. Gilfillan identified all of the principal logical elements behind this conclusion:

Increasing population and/or industry stimulate invention, because they increase the absolute need for a device, and the number of potential finders, while the cost of finding it remains the same. There are more mouths to eat the innovation, so to speak, and more eyes to find it...the difficulty of finding it is no more than before, the value when found is greater, and so, many more inventions are found. We shall speak...of the much vaster increase in the population effective for invention, thru technic and other education...Invention and other kinds of innovation differ from all other pursuits of mankind, in that the proportion of overhead to operating costs is very many fold...More population does not help with more portrait photographs, because more labor must go to make them...But as to invention, increasing population or industry entails that each inventor's work is more widely useful than before, at the same time that there are more inventors to work [1935b, pp. 58-59].

The elements of Gilfillan's argument have been explored, in a more rigorous fashion, in recent models of endogenous innovation. Early one-factor models, e.g. Aghion \& Howitt [1990] and Romer [1988], found that the growth rate was increasing in the size of the economy (population), for precisely the demand and supply reasons emphasized by Gilfillan. Later multi-factor extensions of these same models, e.g. Aghion \& Howitt [1992], Grossman \& Helpman [1991c] and Romer [1990b], showed that the appropriate measure of scale was the supply of factors used intensively in the innovation process, typically assumed to be skilled labour. Increases in other factors of production, such as raw labour, were found to have ambiguous effects, as these raised both the return to innovation (by expanding the total market for new products) and its opportunity cost (by raising the marginal product of skilled labour in non-research sectors). Further extensions to international trade, e.g. Grossman \& Helpman [1991b], raised additional ambiguities, such as when increases in the supply of skilled labour in 
imitative lesser developed economies reduced world growth rates by lowering the return to innovative activity in the developed world. The robust conclusion, however, appears to be that an equiproportional increase in all factors of production or solely in the factors of production used intensively in the innovative (as opposed to imitative) process, increases rates of innovation and growth.'

One of the crucial characteristics of inventive activity identified by Gilfillan, its high ratio of fixed to variable costs, has been elegantly set forth by Romer in two recent papers [1990a,b]. Romer argues that the fundamental characteristic of "technology" is that it is non-rival, i.e. its use in one activity does not bar its use elsewhere. Non-rivalry helps give rise to scale effects, since, ceteris paribus, it translates any uniform increase in the scale of the economy into an unambiguously larger profit flow for each innovator. This characteristic sharply distinguishes the new models of innovation from endogenous growth models based upon the accumulation of rivalrous human or physical capital (e.g. Lucas 1988, Jones \& Manuelli 1990, \& Rebelo 1991), where the aggregate size of the economy, however measured, has no impact on growth rates. ${ }^{2}$

Despite their role as one of the most consistent implications of models of endogenous innovation, scale effects have been the focus of only two of the many empirical studies inspired by the new growth theory. In a cross-sectional analysis Backus, Kehoe and Kehoe [1992], after

${ }^{1}$ This conclusion only holds for models in which new technologies substitute for older technologies, i.e. models in which the return to innovation is decreasing in the rate of innovation. In Young [1993] technologies are allowed to complement each other and, consequently, the return to innovation may be (locally) increasing in the rate of innovation. In this case a rise in the profitability of inventive activity brought about by an increase in market size might actually result in a paradoxical decline in rates of innovation. This conclusion is not, however, globally robust. For large enough rates of innovation, the dominant (pecuniary) interaction between new technologies is substitution, as more and more products compete for a limited market.

${ }^{2}$ Models of learning by doing, in which non-rivalrous knowledge is accumulated in a serendipitous fashion, generally exhibit scale effects (e.g. Young 1991). An exception is Matsuyama (1992), where the accumulation of knowledge is divided by the number of rivalrous entrepreneurs. In linking knowledge with specific entrepreneurs, Matsuyama makes it a rivalrous input in production and thereby purges scale effects from the model. 
an extensive econometric search, discover a significant link between scale and the growth of manufacturing, but can find no significant correlation whatsoever at the aggregate GDP level. In terms of theory, Backus, Kehoe and Kehoe's cross-sectional analysis is somewhat problematic, since the appropriate measure of scale is given by the aggregate market size across which goods and research knowledge flow which, for integrated trading economies, might be poorly correlated with domestic measures of scale. Jones [1995a,b] finesses the problem of measuring scale by analyzing, directly, inputs into the R\&D process. He notes that while the absolute number of R\&D scientists and engineers in the major OECD economies has risen several fold over the past few decades, the total factor productivity growth rates of these economies have remained constant or declined. Thus, while the subject has yet to be analyzed exhaustively, the existing empirical evidence in favour of scale effects might best be described as inconsistent. ${ }^{3}$ This suggests the importance of at least considering how the endogenous process of innovation, characterized by all of the features emphasized by Gilfillan and modern growth theorists, might lead to an outcome where the aggregate resource base devoted to innovation rises, but growth rates do not; i.e., an absence of scale effects.

Jones [1995a] proposes a solution to the scale effects puzzle. Standard models of endogenous innovation assume the existence of strong intertemporal spillovers in innovative activity, wherein innovative activity today increases the absolute productivity of future innovators. Put differently, these models assume that the proportional productivity of innovators remains constant, i.e. knowledge acquired from past innovations allows any innovator, at any

\footnotetext{
${ }^{3}$ In an interesting paper, Kremer (1993) notes that, across the broad sweep of human history, the rate of population growth has been increasing in the level of population, and argues that this is evidence of scale effects. He also notes, however, that this stylized fact is also completely consistent with models which lack scale effects, and, for that matter, with any model in which the rate of population growth is positively related to the level of income per capita (which has trended up along with population).
} 
time, to improve existing technologies by a given percentage. ${ }^{4}$ Jones weakens this assumption, allowing, for example, that the absolute productivity of innovators might be constant (i.e. uninfluenced by past innovation). If so, then as technology advances greater and greater quantities of resources have to be devoted to innovative activity to sustain a given (proportional) growth rate. As such, the model explains the absence of intertemporal scale effects in the OECD experience, where R\&D inputs have risen but growth rates have not. One difficulty with Jones' model, however, is that it does not, in general, allow for sustained growth. If the absolute productivity of innovators does not improve along with productivity in the rest of the economy, then, increasingly, labour will be drawn out of innovation into production and growth will cease. ${ }^{5}$ An increase in market size, expanding the pool of rents, can renew growth, but only temporarily. Thus, fundamentally Jones' model is one which links the level of income to the level of scale, eliminating the influence of scale on growth, but only by purging all long run growth from the model.

Gilfillan, in his time, was also puzzled by the apparent empirical absence of scale effects. ${ }^{6}$ As it so happens, however, he unknowingly provided an answer to the scale effects puzzle, in his principle of "equivalent innovation":

${ }^{4}$ Interestingly, the existence of strong intertemporal spillovers in innovative activity, with current innovation increasing the productivity of future innovators, was also emphasized by Gilfillan (his principle \#11, "Inventions persist").

${ }^{5}$ It was precisely in response to this problem, as it appeared in early exploratory models of endogenous innovation (e.g. Judd 1985 and Grossman and Helpman 1989), that Romer [1990b] first introduced the proportional spillovers assumption.

${ }^{6}$ Although Gilfillan did not have any direct measures of inputs into research and development, he found the constancy of the patents per capita ratio between 1883 and 1933, in the face of the growth of the U.S. market and the increase in technical training, quite troubling. In this regard, Gilfillan's concerns foreshadow the recent academic interest in the post-war decline in the United States and other OECD economies of the ratio of new patents to R\&D scientists/expenditures, e.g. Evenson [1984], Griliches [1989], and Kortum [1993]. 
...inventions are not only duplicated about the same time by identical solutions...but also paralleled by equivalent but unlike means for reaching the same goal around the same time... When Watt needed a guide for his piston rod, he made what he considered his most elegant invention, his "parallel motion. In a book of 1901, I find 20 different ways of doing the same thing...[In] Contraception...we find 18 radically different methods indicated in a recent book, without counting minor variations...In marine history we recall numerous kinds of sails, all for much the same result, the four old methods for shortening sail...the four ways of eliminating the stoker from a powered ship... [A] new configuration of forces [can] call forth a number of independent solutions by different inventors about the same time, some identical and others unlike, even utterly unlike, yet filling the same need [1935b, pp. 137-139].

Increases in market size, in the profitability of inventing a solution to a problem, might call forth a greater variety of potential solutions to that problem, raising the average level of consumer utility. If, however, the continued improvement of this increased variety of technologies requires additional research input, the equilibrium level of $R \& D$ expenditure might rise, without necessarily being associated with an increase in the rate of product quality improvement, i.e. growth.

This paper seeks to develop a model which incorporates Gilfillan's principle of equivalent innovation, while retaining all of the standard features of the new models of endogenous innovation (e.g. non-rivalry and proportional intertemporal knowledge spillovers). My approach is to modify standard "quality ladders" models of product improvement [Aghion and Howitt 1992, Grossman and Helpman 1991c] to allow for an endogenous degree of product variety, which provides an additional channel for the dissipation of the increased rents arising from an increase in market size. As will be shown, the model allows for both the presence and absence of scale effects. When scale effects are absent, policy interventions which are typically seen to influence growth rates, e.g. proportional subsidies to innovation or opening an economy to trade, actually have no effect on the economy's long run growth rate, although they have an important influence on the degree of product variety and, by extension, level of utility. When scale effects are present they may be positive or negative, i.e. increases in market size may lead to reductions 
in the economy's growth rate as the growth in product variety reduces the incentive to improve product quality.

The paper proceeds as follows: Section II presents a simple model of growth without scale effects, building on the Dixit-Stiglitz [1977] formulation of the consumer preference for variety. Section III pauses to relate the model to the existing theoretical literature, arguing that it joins the quality ladders models of endogenous growth with the "level effects" model of Jones. Section IV reformulates the model in the context of the Salop [1979] model of spatial competition, which allows for a more varied characterization of the consumer preference for product variety and quality. This section establishes that the zero scale effects outcome is by no means extreme, providing examples of growth with positive, zero, and negative scale effects. Section V examines the degree of socially optimal scale effects, while Section VI concludes.

\section{A Simple Model of Growth Without Scale Effects}

\section{(i) Model Structure}

Consider an economy populated by L consumers, each of whom inelastically supplies one unit of labour at all times and seeks to maximize the present discounted value of the logarithm of consumption:

(1) $\operatorname{Max} U=\sum_{i=0}^{\infty} \mathrm{B}^{t} \ln [C(t)]$

Output is produced by perfectly competitive firms who combine intermediate inputs in a Dixit-Stiglitz production function:

(2) $Q(t)=\left[\int_{0}^{\infty}\left[\lambda_{i}(t) x_{i}(t)\right]^{\alpha} \mathrm{di}\right]^{\frac{1}{\alpha}}$

where $x_{i}(t)$ and $\lambda_{i}(t)$ denote the quantity and quality, respectively, of intermediate input $\mathrm{i}$ used at time t. 
In this economy, intermediate inputs are produced by monopolistically competitive firms which, in order to produce a given intermediate input at time $t$, must make a fixed (labour) investment in period $\mathrm{t}-1$, with the investment cost increasing in the quality of the good they seek to produce:

$$
\text { (3) } \begin{aligned}
F\left[\lambda_{i}(t), \bar{\lambda}(t-1)\right] & =f e^{\mu \lambda_{i}(t) \bar{\lambda}(t-1)} & \text { if } \quad \lambda_{i}(t) \geq \bar{\lambda}(t-1) \\
& =f e^{\mu} & \text { otherwise }
\end{aligned}
$$

where $\mathrm{f}$ and $\mu$ are constants and $\bar{\lambda}(t-1)$ is an index of technological opportunity, representing the intertemporal spillover of knowledge from previous generations of products. If good $i$ has previously been produced, then $\bar{\lambda}(t-1)$ is given by $\lambda_{i}(\max )$, the highest quality of product $\mathrm{i}$ produced up to time t-1. If good i has never been produced, $\bar{\lambda}(t-1)$ is the average of the $\lambda_{i}(\max )$ 's, which I term $\bar{\lambda}(\max )$. The reader might think of this investment as being made up of two components: a standard production fixed cost of $f e^{\mu}$, independent of quality, and a research cost of $f e^{\mu \lambda_{i}(t) \bar{\lambda}(t-1)}-f e^{\mu}$. Following their fixed investment in period $t-1$, firms may produce any quantity of their product in period $\mathrm{t}$ at a constant marginal (labour) cost of $\mathrm{c}$.

Readers familiar with the "quality ladders" models of Aghion \& Howitt [1992] and Grossman \& Helpman [1991c] will observe that the model described above retains many of the standard features of these models. Firms introduce new, higher quality, versions of old products. These research efforts generate an unappropriated intertemporal spillover, which allows future researchers to generate equivalent increases in quality at a given, time invariant, cost. The model differs from this earlier literature, however, in that it endogenizes the range of available products. This provides an additional avenue for rent dissipation. In standard quality ladders models, increases in the profitability of innovation brought about by, say, an increase in market size can only be dissipated by higher rates of innovation, which destroy the rents of past innovators more 
rapidly. In the model described above, there is an additional degree of freedom, as greater profitability can be dissipated by either increased quality improvements or increased entry. It is this characteristic that allows for the elimination of scale effects in the model. ${ }^{7}$

\section{(ii) General Equilibrium}

As is well known, with logarithmic utility aggregate consumer expenditure, $E(t)$, evolves according to:

(4) $\frac{E(t+1)}{E(t)}=[1+r(t)] \mathrm{B}$

where $r(t)$ is the interest rate between periods $t$ and $t+1$. For a given level of consumer expenditure, maximization on the part of final output producers yields the equally familiar CES demand for each intermediate input:

(5) $\quad x_{i}^{D}(t)=\frac{E(t) p_{i}(t)^{-\varepsilon} \lambda_{i}(t)^{\varepsilon-1}}{\int_{0}^{N(t)} p_{i}(t)^{1-\varepsilon} \lambda_{i}(t)^{\varepsilon-1} \mathrm{di}}, \quad$ where $\varepsilon=\frac{1}{1-\alpha}$ and where $p_{i}(t)$ is the price of product $i$ and $N(t)$ the number of available products, both at time $t$.

In each period potential investors/firms must choose whether or not to enter (incur fixed costs) and, if they enter, must select a product and a level of product quality. As no firm can appropriate the intertemporal knowledge spillover and a fixed cost investment must be made

${ }^{7}$ The model also differs from the standard literature in that firms must bear fixed costs each period and, consequently, a firm's monopoly power lasts only one period. This, however, is not crucial to the results. One could easily transform the model into one with infinitely-lived monopoly power by specifying that the fixed cost in equation (3) above relates, always, to the cost of introducing a completely new product, with $\bar{\lambda}(t-1)$ given by the average quality of products introduced in period $\mathrm{t}-1$. In that case, $\mathrm{N}(\mathrm{t})$ new products of quality $\lambda(t)$ will be introduced in each period and, at any time, an infinite number of products of varying quality (characterized as the sequence $\{N(i), \lambda(i)\}_{i=-\infty}^{\prime}$ ) will be produced in the economy. This complicates the algebra, but changes none of the fundamental results described in the sections below. 
each period, each firm's decision horizon is only one period long. Since, regardless of market structure, firm returns will always be increasing in the level of product quality, there is no gain to incurring the fixed cost $f e^{\mu}$ to produce less than the state of the art quality. Consequently, at time $\mathrm{t}-1 \lambda_{i}(\max )$ in each industry will always be given by $\lambda_{i}(t-1)$. Since all industries are symmetrical, in equilibrium product quality will be the same in each sector, i.e.

$\bar{\lambda}(\max )=\lambda_{i}(t-1)=\lambda(t-1)$. Thus, firms will face the same costs whether they improve an existing product or introduce a new one and, since monopoly profits always exceed individual firm profits under duopoly, no two firms will choose to produce the same product. Finally, since all firms are infinitesimally small, there will be no strategic interactions and intermediate input production, in each period, will take place under conditions of symmetric monopolistic competition.

In sum, the entry problem for each firm can be reduced to one of selecting, in period $\mathrm{t}-1$, a period t product quality and price so as to maximize net discounted monopolistically competitive profits:

(6) $\operatorname{Max}_{p_{i}(t), \lambda_{i}(t)} \frac{\left[p_{i}(t)-c\right] x_{i}^{D}(t)}{1+r(t-1)}-F\left[\lambda_{i}(t), \lambda(t-1)\right]$

where I have taken labour as the numeraire, i.e. set the wage rate equal to 1 . Differentiating with respect to $p_{i}(t)$ and $\lambda_{i}(t)$ provides two first order conditions:

(7) $x_{i}^{D}(t)+\left[p_{i}(t)-c\right] \frac{\partial x_{i}^{D}(t)}{\partial p_{i}(t)}=0$

(8) $\left(\frac{p_{i}(t)-c}{1+r(t-1)}\right) \frac{\partial x_{i}^{D}(t)}{\partial \lambda_{i}(t)}-\frac{\partial F\left[\lambda_{i}(t), \bar{\lambda}(t-1)\right]}{\partial \lambda_{i}(t)}=0$

while free entry implies that net profits will be zero:

(9) $F\left[\lambda_{i}(t), \bar{\lambda}(t-1)\right]=\frac{\left[p_{i}(t)-c\right] x_{i}^{D}(t)}{1+r(t-1)}$ 
Dividing (8) by (9) and making using of the symmetry of the problem allows one to rearrange (7) and (8) so as to provide the key equilibrium relations:

$$
\begin{aligned}
& \text { (10) } \frac{p-c}{p}=\frac{1}{\mathrm{E}_{p_{i}}^{x_{i}}} \\
& \text { (11) } \mathrm{E}_{\lambda_{i}}^{F}=\mathrm{E}_{\lambda_{i}}^{x_{i}^{D}}
\end{aligned}
$$

where $E_{j}^{i}$ denotes the elasticity of $i$ with respect to $j$. Equation (10) is the familiar monopoly pricing relation, which states that firms set prices so as to equate the unit profit margin with the inverse of the elasticity of demand. Equation (11) indicates that firms select product quality so as to equate the elasticity of the research cost with respect to quality (the cost) to the elasticity of demand with respect to that variable (the benefit). For the CES demand of the model, these relations take the following functional forms:

$$
\begin{aligned}
& (10)^{\prime} \frac{p-c}{p}=\frac{1}{\varepsilon}=1-\alpha \\
& (11)^{\prime} \mu \frac{\lambda(t)}{\lambda(t-1)}=\varepsilon-1=\frac{\alpha}{1-\alpha}
\end{aligned}
$$

where I have assumed that $\varepsilon-1 / \mu>1$, i.e. that products are improved in equilibrium. With both the elasticity of demand with respect to price and the elasticity of demand with respect to quality independent of the size of the market and the number of entrants, the equilibrium markup and rate of product improvement are both completely determined by parameters of the research and production functions.

Turning to the labour market, equilibrium here requires that the total labour used in manufacturing and investment/research equal the available supply, $L$. The labour used in manufacturing simply equals total consumer expenditure divided by the price per unit (of each symmetric good) times the unit marginal cost, i.e.: 


$$
L_{M}(t)=\frac{E(t)}{p} c=\alpha E(t)
$$

while the labour used in research equals the number of entrants times the research investment per firm:

$$
L_{R}(t)=N(t+1) f e^{\mu \lambda(t+1) \nu \lambda(t)}
$$

Consequently, labour market clearing requires that:

$$
L=\alpha E(t)+N(t+1) f e^{\mu \lambda(t+1) \lambda \lambda(t)}
$$

To determine the equilibrium number of products, I begin by noting that, in the symmetric equilibrium, the free entry relation, (9) above, reduces to:

$$
f e^{\mu \lambda(t) \lambda(t-1)}=\frac{(1-\alpha) E(t)}{N(t)[1+r(t-1)]}
$$

Advancing (15) one period, substituting into (14), and making use of the first order condition for the growth of consumer expenditure (4), allows one to solve for the value of consumer expenditure as a function of the various parameters:

$$
L=\alpha E(t)+\frac{(1-\alpha) E(t+1)}{1+r(t)}=E(t)[\alpha+(1-\alpha) B]
$$

or:

$$
(16)^{\prime} \quad E(t)=L /[\alpha+(1-\alpha) \mathrm{B}]
$$

Thus, equilibrium requires that the economy move immediately to a steady state level of consumer expenditure, with a constant interest rate $1+r=\mathrm{B}^{-1}$. Substituting (16) back into (15) and rearranging solves for the total number of entrants (in any period) as a function of the parameters of the model and the aggregate market size (as given by $\mathrm{L}$ ):

(17) $\quad N=\frac{(1-\alpha) E(t)}{[1+r(t-1)] f e^{\mu \lambda(t) / \lambda(t-1)}}=\frac{(1-\alpha) \mathrm{B} L}{[\alpha+(1-\alpha) \mathrm{B}] f e^{\varepsilon-1}}$ 
In sum, each period $\mathrm{N}$ firms (as given by (17)) invest in $\mathrm{R} \& \mathrm{D}$, improving the current generation of products by a factor of $\varepsilon-1 / \mu$. In the following period these firms compete monopolistically in the production of intermediate inputs, charging a common price $p=c / \alpha$. Consumer expenditure is constant, as is the rate of interest and the share of labour in research and manufacturing.

\section{(iii) Scale Effects, in Growth Rates and Levels}

To examine the impact of scale on the growth and level of income in this economy it is useful to first derive an expression for output per capita. To this end, from equation (2) earlier we can see that in the symmetric equilibrium the total output of the economy is given by:

$$
Q(t)=\lambda(t) \bar{x}(t) N(t)^{\frac{1}{\alpha}}
$$

where $\bar{x}(t)$, the demand for each intermediate input, in turn equals:

$$
\text { (19) } \bar{x}(t)=\frac{E(t)}{p(t) N(t)}=\frac{\alpha L(t)}{c[\alpha+(1-\alpha) \mathrm{B}] N(t)}
$$

Consequently, output per capita, $q(t)$, is given by:

$$
\text { (20) } q(t)=\frac{\alpha \lambda(t) N(t)^{\frac{1-\alpha}{\alpha}}}{c[\alpha+(1-\alpha) \mathrm{B}]}
$$

In equilibrium the number of varieties $(\mathrm{N})$ is constant. Thus, long run growth in this economy is driven by the growth of product quality. Since, however, the elasticity of demand with respect to product quality is independent of the scale of the economy, changes in this variable have no implications for the long run growth of output per capita, which is simply given by $\lambda(t) / \lambda(t-1)=\varepsilon-1 / \mu$. The total number of product varieties, $N$, is, however, linearly related to the level of $\mathrm{L}$. Thus, the level of utility is related to the level of scale. A larger market calls forth additional differentiated solutions to general needs. If technology is non-rivalrous, as in 
this model, this greater variety of solutions is available to all, and, hence, unambiguously raises the level of welfare. ${ }^{8}$

Since the level of utility is related to the level of scale, changes in scale will generate important transitional (i.e. temporary) dynamics in growth rates. From (20), we see that the logarithmic growth of output per capita between any two periods is given by:

$$
\ln \left[\frac{q(t)}{q(t-1)}\right]=\ln \left[\frac{\lambda(t)}{\lambda(t-1)}\right]+\left(\frac{1-\alpha}{\alpha}\right) \ln \left[\frac{N(t)}{N(t-1)}\right]=\ln \left[\frac{\varepsilon-1}{\mu}\right]+\left(\frac{1-\alpha}{\alpha}\right) \ln \left[\frac{L(t)}{L(t-1)}\right]
$$

Thus, the growth of the economy between any two periods can be decomposed into a long run component and a transitional element due to changes in scale. In a manner similar to the role of capital accumulation in the neo-classical growth model, these level effects could be of considerable quantitative significance and deserving of careful investigation. The distinction between levels and growth rates remains a useful one, however, as the underlying sustainable growth rate of economies in which measures of scale have been rising rapidly might be well below their historical experience. ${ }^{9}$

The absence of scale effects (in growth rates) in the model indicates that any policy action which simply enlarges or contracts the total pool of rents available to inventive entrepreneurs will only influence the level of income, without changing its long run growth rate. Thus,

\footnotetext{
${ }^{8}$ This conclusion applies even when consumers have most preferred varieties, as in the Salop model of preferences used in section IV of this paper. In that case, a greater variety of solutions creates a better match between the available technologies and the preferences of consumers.

${ }^{9}$ Jones [1994] makes this observation with regards to the OECD. I should note that if the scale of the economy grows steadily in equilibrium, say due to population growth, then the "transitional" level effects will, of course, contribute in a continuing fashion to aggregate growth. The distinction between level and growth effects nevertheless remains useful. As Jones notes, the percentage of the labour force in the OECD devoted to R\&D has been rising through time. This has contributed to a transitional increase in the level of output (i.e. growth rates) well in excess of the sustainable rate (i.e. in excess of the "transitional" component due to continuing population growth).
} 
consider the movement of two identical economies from a position of autarky to one of free trade. In the integrated trading equilibrium, this policy change is describable as an increase in the labour force of a unified economy from $\mathrm{L}$ to $2 \mathrm{~L}$. From (17) earlier above, we see that the number of available varieties doubles. Each economy produces as many varieties as before and maintains the same output per variety. Consumption per variety falls, however, as each economy trades half of its intermediate output for half of the differentiated intermediate output of the other economy. The rise in intermediate variety, however, more than offsets the fall in intermediate quantity, raising the level of final goods output in both economies. ${ }^{10}$ The elasticity of demand with respect to quality, and hence the growth rate of both economies, remains, however, unchanged.

One can easily see how many policy interventions, which in contemporary models of endogenous innovation influence the the long growth of the economy, will be ineffective (in growth rates) in this model. Thus, the imposition of tariffs, either on a unilateral or multilateral basis, or the provision of proportional $R \& D$ subsidies (which rebate a fixed share of $R \& D$ expenditures), will change the total pool of rents available to entrepreneurs without, however, influencing the elasticity of demand with respect to product quality. These policies will influence the level of income, without changing its long run growth rate. Other policies do exist, however, which will influence both the level and growth rate of income. Thus, quotas or an $R \& D$ subsidy based upon the intensity of $R \& D$ effort (one which is increasing in the degree to which the research increases the quality of current inputs) will change the elasticity of demand and the elasticity of research costs with respect to product quality, respectively, leading, in equilibrium, to changes in the both the level and growth rate of output per capita.

\footnotetext{
${ }^{10}$ In terms of equation (18) earlier above, $\bar{x}$ is halved, but $\mathrm{N}$ is doubled, raising output by a factor of $2^{(1-\alpha) / \alpha}$.
} 


\section{Discussion of the Model}

Innovation in the model described above has two dimensions, a vertical dimension and a horizontal dimension. As such, it might appear, at first blush, that the model marries the vertical "product quality" models of Aghion \& Howitt [1992] and Grossman and Helpman [1991c] to the horizontal "product variety" model of Romer [1990b]. This is not actually true. In both the vertical and horizontal models of innovation there exists an intertemporal spillover whereby innovation today lowers innovation costs in the future. In the model described in the preceeding section, there exists an intertemporal knowledge spillover in the vertical dimension, but there is no such spillover in the horizontal dimension. To incorporate a knowledge spillover in the horizontal dimension similar to that of Romer, the model would have to specify that the costs of innovation are given by:

$$
F\left[\lambda_{i}(t), \bar{\lambda}(t-1), N(t-1)\right]=\frac{f e^{\mu \lambda_{i}(t) \bar{\pi}(t-1)}}{N(t-1)}
$$

In this case, the cost of innovation is inversely related to the existing degree of product variety.

It is instructive to work out the equilibrium of the model when there exists a horizontal knowledge spillover of the form described in (22) above. Most of the equilibrium relations of the model remain as before. In particular, $(10)^{\prime}$ and $(11)^{\prime}$, describing the equilibrium intermediate input price and rate of quality improvement, are unchanged, as is $(16)^{\prime}$, which pins down the steady state level of expenditure." The functional form of the free entry condition, however, changes in a non-trivial fashion, becoming:

\footnotetext{
${ }^{11}$ The labour market clearing relation, (14), becomes:

$L=\alpha E(t)+\frac{N(t+1) f e^{\mu \lambda(t+1) / \lambda(t)}}{N(t)}$
}

Substituting using the free entry condition (22) above and the first order condition for consumer expenditure, (4), one finds, however, that the equilibrium level of consumer expenditure is unchanged. 
(23) $\frac{f e^{\mu \lambda(t) \lambda(t-1)}}{N(t-1)}=\frac{\left[p_{i}(t)-c\right] x_{i}^{D}(t)}{1+r(t-1)}=\frac{(1-\alpha) E(t)}{N(t)[1+r(t-1)]}=\frac{(1-\alpha) \mathrm{B} L}{N(t)[\alpha+(1-\alpha) \mathrm{B}]}$

Rearranging, we find that:

$$
\frac{N(t)}{N(t-1)}=\frac{(1-\alpha) \mathrm{B} L}{f e^{\varepsilon-1}[\alpha+(1-\alpha) \mathrm{B}]}
$$

Unlike the model without a horizontal knowledge spillover, product variety now grows steadily over time. ${ }^{12}$ Although the growth rate of product quality, $\lambda(t) / \lambda(t-1)$, remains fixed at $\varepsilon-1 / \mu$, the growth rate of product variety is now an increasing function of the scale of the economy. The economy once again exhibits scale effects in growth rates.

Intertemporal spillovers play a crucial role in models of innovation, as they allow innovative activity to sustain growth at a constant, time invariant, resource cost. As noted by Jones [1995a], when the intertemporal spillover is not sufficiently strong to allow for constant cost growth, the growth rate of the economy asymptotes to zero. ${ }^{13}$ The model of this paper combines two forms of innovative activity, one of which can lead to sustained growth (vertical quality improvements) and the other which cannot (horizontal product introduction). As such,

\footnotetext{
${ }^{12}$ I assume that the parameters are such as to ensure that $\mathrm{N}$ is growing, rather than contracting, over time. Specifying that the research cost relates to the once and for all cost of introducing a new product, which can then be produced at a marginal cost of $\mathrm{c}$ in all subsequent periods, avoids this problem, but complicates the algebra substantially.
}

${ }^{13}$ Jones, in a horizontal model of product introduction, specifies that new products are introduced according to the research function:

$$
\dot{N}(t)=N(t)^{\phi} L_{R}(t)
$$

and notes that when $\phi<1$ the economy's growth rate goes to zero. Thus, even if there are intertemporal spillovers, if these are not large enough to allow for constant cost growth, the development of the economy grinds to a halt. Following Jones' analytical framework, the research cost in this paper might be specified as:

$$
\frac{f e^{\frac{\mu_{i}(t)}{\left.\bar{\lambda}_{(t}-1\right)^{\gamma}}}}{N(t-1)^{\phi}}
$$

For sustained growth to occur it is necessary that either $\gamma$ or $\phi$ be greater than or equal to 1 . 
the model is more accurately described as a marriage of the quality ladders models with the "level effects" models of horizontal innovation, such as Judd [1985], Grossman and Helpman [1989] and Jones [1995a]. Scale need now no longer be positively associated with growth, as the "level effects" innovative dimension can completely dissipate the increased pool of rents brought about by a rise in market size, without leading to any rise in innovative activity along the dimension that leads to sustainable growth. This point can be considered as being more general than the one or two dimensional analysis of the model. If there are $\mathrm{M}$ dimensions where innovative activity can lead to sustained growth, but one additional dimension where spillovers are insufficient to lead to growth, then increases in rents can be dissipated, generating level changes in income, without changing the long run growth rate of the economy.

From the above, the reader might conclude that the results of the model described in the preceeding section are an extreme outcome. Increases in rents might be exhausted by greater innovative activity along a "growth" dimension and/or a "level" dimension and, in general, one would expect the impact of any increase in market size to occur along both dimensions, leading to a rise in both the level of income and its growth rate. Thus, the case where increases in scale have purely level effects would seem to be an extreme outcome. This intuition, is, however, incorrect. Recall the crucial first order conditions analyzed earlier in section II, in particular that governing the optimal rate of quality improvement for innovating firms:

$$
\text { (25) } \quad \mathrm{E}_{\lambda_{i}}^{F}=\mathrm{E}_{\lambda_{i}}^{x_{i}^{D}}
$$

In equilibrium, firms set the elasticity of the research cost with respect to product improvement equal to the elasticity of demand with respect to that variable. With Dixit-Stiglitz preferences, the elasticity of demand with respect to quality is independent of the number of entering firms. More generally, however, the elasticity of demand with respect to quality might be an increasing or decreasing function of the number of entrants. In the latter case, an increase in innovative 
activity along the horizontal dimension, brought about by an increase in market size, would, in equilibrium, lead to lower rates of product improvement. In other words, increased innovative activity along the "level" dimension could easily have adverse effects on innovative activity in the "growth" dimension, lowering the overall growth rate of the economy. In this sense, the results of the model described above are not in the least extreme, growth in an economy could be a positive, neutral, or decreasing function of the scale of the economy. Section IV below makes use of the more varied patterns of demand derivable from the Salop [1979] model of spatial competition to establish this point analytically.

\section{Growth With and Without (Positive and Negative) Scale Effects}

This section uses the Salop model of spatial competition to derive more varied analytical results. I begin by presenting the partial equilibrium Salop structure and then embed this structure in a general equilibrium model, providing examples of growth both with and without (positive and negative) scale effects.

\section{(i) Partial Equilibrium}

Imagine that there are D consumers located uniformly along the unit circle, each of whom inelastically demands one unit of a "product" and seeks to maximize the surplus, net of price and transportation costs, derived from its consumption:

$$
\underset{\{i\}}{\operatorname{Max}} q \lambda_{i}-p_{i}-d(v-i)
$$

where $v$ denotes the location of the consumer, $i$ the location of the producer (also along the unit circle), $\lambda_{i}$ and $p_{i}$ the quality and price of the producer's output, and $q$ the consumer's marginal valuation of product quality. $d(\cdot)$ represents a transport cost paid by the consumer, with $d(0) \geq 0$, 
$d^{\prime}(x)>0$ and $d^{\prime \prime}(x)>0$ for all $x>0 .{ }^{14}$ Later on, I shall use variation in the functional form of $d(\cdot)$ to derive differing types of scale effects.

In this economy, a firm can produce output at a point along the unit circle by incurring a fixed cost of entry increasing in the quality of the product it seeks to produce:

$$
F\left(\lambda_{i}, \bar{\lambda}\right)=f(1+r) e^{\mu \lambda_{i} / \bar{\lambda}}
$$

where $\bar{\lambda}$ is an index of technological opportunity and $f, r$ and $\mu$ are constants. There is free entry. Following Salop, I assume that all entrants are automatically located equidistantly along the unit circle and focus on the Nash equilibrium in product quality and price. ${ }^{15}$

Although there might be $\mathrm{N}$ entrants, in the symmetric equidistant equilibrium each firm really only competes with its neighbours to the left and right. Consider the competition between firm $\mathrm{i}$ and firm $\mathrm{i}+1$ located $1 / \mathrm{N}$ to its right. Since consumers seek to maximize their net surplus, and since $d(\cdot)$ is strictly increasing, firm i knows that it will garner a right-hand side market share (i.e. arc length) equal to $x \in(0,1 / \mathrm{N})$, where $\mathrm{x}$ is the point at which the marginal consumer is indifferent between firm i's output and that of firm $\mathrm{i}+1$ :

$$
q \lambda_{i}-p_{i}-d(x)=q \lambda-p-d(1 / N-x)
$$

where $p$ and $\lambda$ denote the price and product quality of firm $i+1$ (and all of the other symmetric firms in the economy). Totally differentiating (28) provides measures of the sensitivity of firm i's one-sided market share to its price and product quality:

${ }^{14}$ Throughout this paper, primes and double primes (when applied to functions) denote first and second derivatives, respectively. The assumption on $d^{\prime \prime}$ ensures that Salop's [1979] supercompetitive equilibrium, in which firms discontinuously capture market share, never arises (the analytics are discussed in a footnote further below), thereby ensuring that a Nash equilibrium always exists.

${ }^{15}$ Economides [1989] endogenizes firm locations, analyzing the Salop entry problem as a three stage game, in which firms enter, choose their location (without quality differentiation), and then choose prices. He shows that for a quadratic distance function there exists a subgame perfect equilibrium with symmetric prices and locations. 
(29) $\frac{\mathrm{d} x}{\mathrm{~d} p_{i}}=\frac{-1}{d^{\prime}(x)+d^{\prime}(1 / N-x)} \quad \frac{\mathrm{d} x}{\mathrm{~d} \lambda_{i}}=\frac{q}{d^{\prime}(x)+d^{\prime}(1 / N-x)}$

Conditional upon (28) and the Nash equilibrium assumption, the analytical problem facing each entering firm is to select a product quality and price so as to:

(30) $\underset{p_{i}, \lambda_{i}}{\operatorname{Max}_{i}}\left[p_{i}-c\right] 2 D x\left(p_{i}, \lambda_{i}, p, \lambda\right)-F\left(\lambda_{i}, \bar{\lambda}\right)$

where $c$ is the marginal cost of production. To simplify the algebra, in what follows I assume that $c=0$.

Maximization of (30) yields the usual first order conditions:

(31) $p_{i}=\frac{-x}{\partial x / \partial p_{i}}$

(32) $\partial F / \partial \lambda_{i}=2 p_{i} D \partial x / \partial \lambda_{i}$

While free entry ensures that:

(33) $F(\lambda, \bar{\lambda})=2 p D x=\frac{p D}{N}$

where I have made use of the fact that in the symmetric equilibrium each firm's one-sided market share (x) equals $1 / 2 \mathrm{~N}$. Dividing (32) by (33), imposing symmetry, and making use of (29) allows us to re-express (31) and (32) as:

$$
\begin{aligned}
& \text { (31)' } p=\frac{d^{\prime}\left(\frac{1}{2 N}\right)}{N} \\
& (32)^{\prime} \frac{\mu \lambda}{\bar{\lambda}}=\frac{q \lambda}{\left\{\frac{d\left(\frac{1}{2 N}\right)}{N}\right\}}=\frac{q \lambda}{p}
\end{aligned}
$$


Equations (31)' and (32)' are, of course, nothing more than equations (10) and (11) from the Dixit-Stiglitz free entry problem applied to the case of the Salop model with both quality and price competition. $^{16}$

\section{(ii) Closing the Model}

To integrate the Salop model delineated above into a general equilibrium setting, one merely has to redefine the D locational "consumers" as the total demand for capital services in the economy. Specifically, imagine that the production of final output requires the performance of an equal quantity of differentiated tasks (indexed along the unit circle), with productivity a function of the average quality with which the tasks are performed:

$$
\begin{gathered}
Q(t)=\lambda(t) \operatorname{Min}\left\{x_{v}(t) \mid v \in[0,1]\right\} \\
\text { where } \lambda(t)=\int_{0}^{1} \lambda_{v}(t) \mathrm{d} v
\end{gathered}
$$

and where $x_{v}(t)$ is the quantity of task $v$ performed at time $\mathrm{t}$ and $\lambda_{\nu}(t)$ is its quality. To perform a particular production task, firms make use of capital and labour inputs. Capital goods are specialized, in that they are ideally suited for the performance of some tasks, and less suited for others. The specificity of capital inputs is denoted by their index along the unit circle and the

${ }^{16}$ If $d^{\prime \prime}$ is allowed to be less than or equal to zero a discontinuity in the firm's profit function may arise and, consequently, the symmetric Nash equilibrium described above may not exist. In this case, firm i may select a price and product quality so as to make consumers at firm $i+1$ 's production location indifferent between purchases from firm $i$ and firm i+1, i.e. $q \lambda_{i}-p_{i}-d(1 / N)=q \lambda-p-d(0)$. If so, and if $d^{\prime}(1 / N)<d^{\prime}(0)$, then firm i will also discontinuously capture part (or all) of firm $i+1$ 's remaining right-hand side market share. If the profits from this action exceed zero, then the equilibrium described above does not exist. Assuming that $d^{\prime \prime}$ is always greater than zero (as was done above), is sufficient to guarantee that this problem does not arise, i.e. that the symmetric zero profit Nash equilibrium always exists. 
quantity of labour input required to perform a particular task is increasing in the distance between the differentiated location of the capital service and that of the task it is used to perform: $:^{17}$

$$
x_{v}(t)=\operatorname{Min}\left\{q_{i_{v}}(t), \frac{L_{v}(t)}{d\left(v-i_{v}\right)}\right\}
$$

where $i_{v}$ denotes the unit circle location of the type of capital used in the performance of task $v$, $q_{i_{v}}(t)$ is the quantity of capital used, $L_{v}(t)$ the quantity of labour, and $d(\cdot)$ is the distance function encountered earlier above. The quality of task $x_{v}(t)$ is determined by the quality of the capital good used in its production, i.e. $\lambda_{v}(t)=\lambda_{i_{v}}(t)$.

Final goods output is produced by perfectly competitive firms. Consider the problem faced by a firm trying to maximize the profits derived from production involving the performance of one unit of each task, i.e.:

(36) $\operatorname{Max} \int_{0}^{1} p_{Q}(t) \lambda_{i_{v}}(t)-p_{i_{v}}(t)-d\left(v-i_{v}\right) d v$

where I have let labour be the numeraire and where $p_{i_{v}}(t)$ denotes the price of the capital input $\mathrm{i}$ used in the performance of task $v$ and $\mathrm{p}_{\mathrm{Q}}(\mathrm{t})$ is the firm's marginal valuation of task quality, which is simply the competitive price of final goods output. Since the firm is free to choose a different capital service producer for each task, the firm's problem can be reduced to one of maximizing the net surplus from the performance of each task:

$$
\underset{\{i\}}{\operatorname{Max}} p_{Q}(t) \lambda_{i}(t)-p_{i}(t)-d(v-i)
$$

${ }^{17}$ To provide an example, some software packages are ideally suited to run cross-section regressions, whereas others are perfect for time series analysis. Most packages, however, can perform both types of analysis, one merely has to apply additional labour input to get the package to perform the type of regression for which it is not ideally suited. 
Clearly, equation (37) is identical to equation (26) in the earlier partial equilibrium model. The total quantity of capital services demanded will equal $D(t)=\int_{0} x_{\nu}(t)=Q(t) / \lambda(t)$, and this demand will be distributed uniformly along the unit circle.

Turning to the producers of innovative capital services, these are, of course, simply the differentiated output producers of the partial equilibrium model described earlier. To provide capital services of quality $\lambda_{i}(t)$ at location $i$ in period $t$, firms must make a labour investment of $f e^{\mu \lambda_{i}(t) \bar{\pi}(t-1)}$ in period $t-1$, where $\bar{\lambda}(t-1)$ is the average quality of capital services provided in period t-1. ${ }^{18}$ There is free entry into innovation, but all entrants are exogenously constrained to be located equidistantly along the unit circle. Taking as given the actions of all other firms, each entrant will select a product quality and price so as to maximize net period t profits (inclusive of the interest cost of the period $t-1$ investment):

(38) $\underset{p_{i}(t), \lambda_{i}(t)}{\operatorname{Max}} 2 p_{i}(t) D(t) x\left[p_{i}(t), \lambda_{i}(t), p(t), \lambda(t)\right]-[1+r(t-1)] f e^{\mu \lambda_{i}(t) \bar{\pi}(t-1)}$

where $r(t-1)$ is the endogenously determined period $t-1$ interest rate, $D(t)$ is the total demand for capital services at time $t$, and $x$, the firm's one-sided market share, is determined by equation (28) earlier above. To close the model, I assume, as before, that there are L consumers, each of whom inelastically supplies one unit of labour and seeks to maximize the present discounted value of the logarithm of final goods consumption:

$$
\operatorname{Max} U=\sum_{t=0}^{\infty} \mathrm{B}^{t} \ln [C(t)]
$$

${ }^{18}$ As in the preceeding model, if $\lambda_{i}(t)$ is less than or equal to $\bar{\lambda}(t-1)$, then the entry cost is simply $f e^{\mu}$. To simplify the discussion, in what follows I will assume that $\mu$ is sufficiently small to ensure that capital goods are improved in equilibrium. I will also ignore integer constraints on N. 


\section{(iii) General Equilibrium}

To solve the model, I begin by noting that, conditional upon a given level of capital service demand, marginal valuation of product quality, and market rate of interest, the number of capital service producers and the quality improvement and price selected by each such producer have already been determined by equations $(31)^{\prime},(32)^{\prime}$ and (33) in the partial equilibrium analysis earlier above. In the notation of the general equilibrium problem, these equations are:

$$
\begin{aligned}
& (31)^{\prime} \quad p(t)=\frac{d^{\prime}\left(\frac{1}{2 N(t)}\right)}{N(t)} \\
& (32)^{\prime} \frac{\mu \lambda(t)}{\lambda(t-1)}=\frac{q(t) \lambda(t)}{p(t)}=\frac{p_{Q}(t) \lambda(t)}{p(t)} \\
& \text { (33) }\left[(1+r(t-1)] f e^{\mu \lambda(t)) \lambda(t-1)}=\frac{p(t) D(t)}{N(t)}\right.
\end{aligned}
$$

where I have made use of the fact that in the symmetric equilibrium all capital service innovators select the same level of product quality, i.e. $\lambda_{i}(t)=\bar{\lambda}(t)=\lambda(t)$. With these relations, it remains merely to solve for the endogenous rate of interest, the price of final goods output, and the level of capital service demand. ${ }^{19}$ In what follows I restrict my analysis to the steady state, dropping the notation with respect to time.

Along any steady state path, consumer expenditure must be constant which, for exponentially discounted logarithmic utility, implies that:

$$
\text { (40) } 1+r=\frac{1}{\mathrm{~B}}
$$

Under perfect competition, profits in final goods production will be zero. Thus, from equation (36) earlier, the price of final goods output is given by:

${ }^{19}$ In the partial equilibrium analysis, innovators took these variables as given. In the general equilibrium setting outlined above, this is not strictly correct, as there are only $\mathrm{N}$ (integer) innovators, and the actions of each innovator will indeed influence the level and price 


$$
p_{Q}=\frac{p}{\lambda}+\frac{2 N \int_{0}^{\frac{1}{2 N}} d(x) \mathrm{d} x}{\lambda}
$$

where I have made use of the fact that in equilibrium each capital service producer commands a market share of length $1 / 2 \mathrm{~N}$ to the left and right of her position on the unit circle. The price of output has two components, the first term represents the price of the capital services used in the production of final goods $(p / \lambda)$, while the second represents the labour used in the production of one unit of output, i.e. the unit labour requirement $\left(L_{1}\right)$.

Labour market equilibrium requires that the labour used in manufacturing $\left(L_{M}\right)$ and research $\left(L_{R}\right)$ equal the total supply. The labour used in research will equal the total number of capital producers times the research cost per producer, or $N f e^{\mu g}$, where g denotes the steady state period by period improvement in product quality, $\lambda(t) / \lambda(t-1)$. Consequently, the total demand for capital services is given by:

$$
D=\frac{Q}{\lambda}=\frac{L_{M}}{L_{1} \lambda}=\frac{L-N f e^{\mu g}}{2 N \int_{0}^{\frac{1}{2 N}} d(x) \mathrm{dx}}
$$

of output and the market rate of interest. This complication can easily be avoided, however, by assuming that the production of final output requires the performance of a continuum $[0,1]$ of task "types", with each type, in turn, composed of a unit circle continuum of tasks:

$$
Q(t)=\lambda(t) \operatorname{Min}\left\{x_{u v}(t) \mid u \in[0,1], v \in[0,1]\right\}
$$

$$
\text { where } \lambda(t)=\int_{0}^{1} \int_{0}^{1} \lambda_{u v}(t) d u d v
$$

In this case, if each set of capital goods, $\mathrm{N}_{\mathrm{u}}$, is specific to the production of a particular task type, then no individual innovator will have any impact on any of the macroeconomic variables. Rather than clutter up the analysis with layers of algebra designed to make each innovator small in the aggregate economy, I will simply proceed with the assumption that innovators take these general equilibrium variables as given. 
Putting the above together provides two relations which govern the degree of product quality improvement $(\mathrm{g})$ and number of entrants $(\mathrm{N})$ in the steady state:

$$
\begin{aligned}
& \mu g=\frac{p_{Q} \lambda}{p}=\frac{p+L_{1} \lambda}{p}=1+\frac{2 N \int_{0}^{\frac{1}{2 N}} d(x) \mathrm{dx}}{\frac{d\left(\frac{1}{2 N}\right)}{N}} \\
& f e^{\mu g}=\mathrm{B} \frac{p D}{N}=\mathrm{B} \frac{p\left(\frac{L_{M}}{L_{1} \lambda}\right)}{N}=\mathrm{B}\left(\frac{p}{L_{1} \lambda}\right)\left(\frac{L}{N}-f e^{\mu g}\right)
\end{aligned}
$$

Equation (43) is the, by now familiar, firm optimality relation which states that firms set the elasticity of the research cost with respect to product quality $(\mu g)$ equal to the elasticity of demand with respect to product quality, which, in equilibrium, depends upon the price of final goods output relative to the price of capital services. A higher price of output implies a greater marginal valuation of product quality, and hence a larger elasticity of demand with respect to that variable. A higher price of capital services is, from (31)' above, related to a larger marginal cost of distance and, hence, to a lower demand response for any given change in product quality or price. Substituting for the price of output, which depends upon capital service prices, we see that the elasticity of demand with respect to product quality is a function of the ratio of the unit labour requirement to the price of capital services. Both terms are decreasing in $\mathrm{N}$, as a reduction in the distance between firms both increases competitive pressures (as $d^{\prime}$ declines, the proportional gain from price reductions or quality improvements rises) and improves the technological efficiency of production (as each task may now be performed with a more compatible technology). Depending upon which effect dominates, the elasticity (EE) relation may be upward or downward sloping in $[\mathrm{N}, \mathrm{g}]$ space. Various examples are drawn in figure I.

Equation (44), the free entry relation, equates the research cost per innovator to their 
Figure I: Growth With and Without Scale Effects

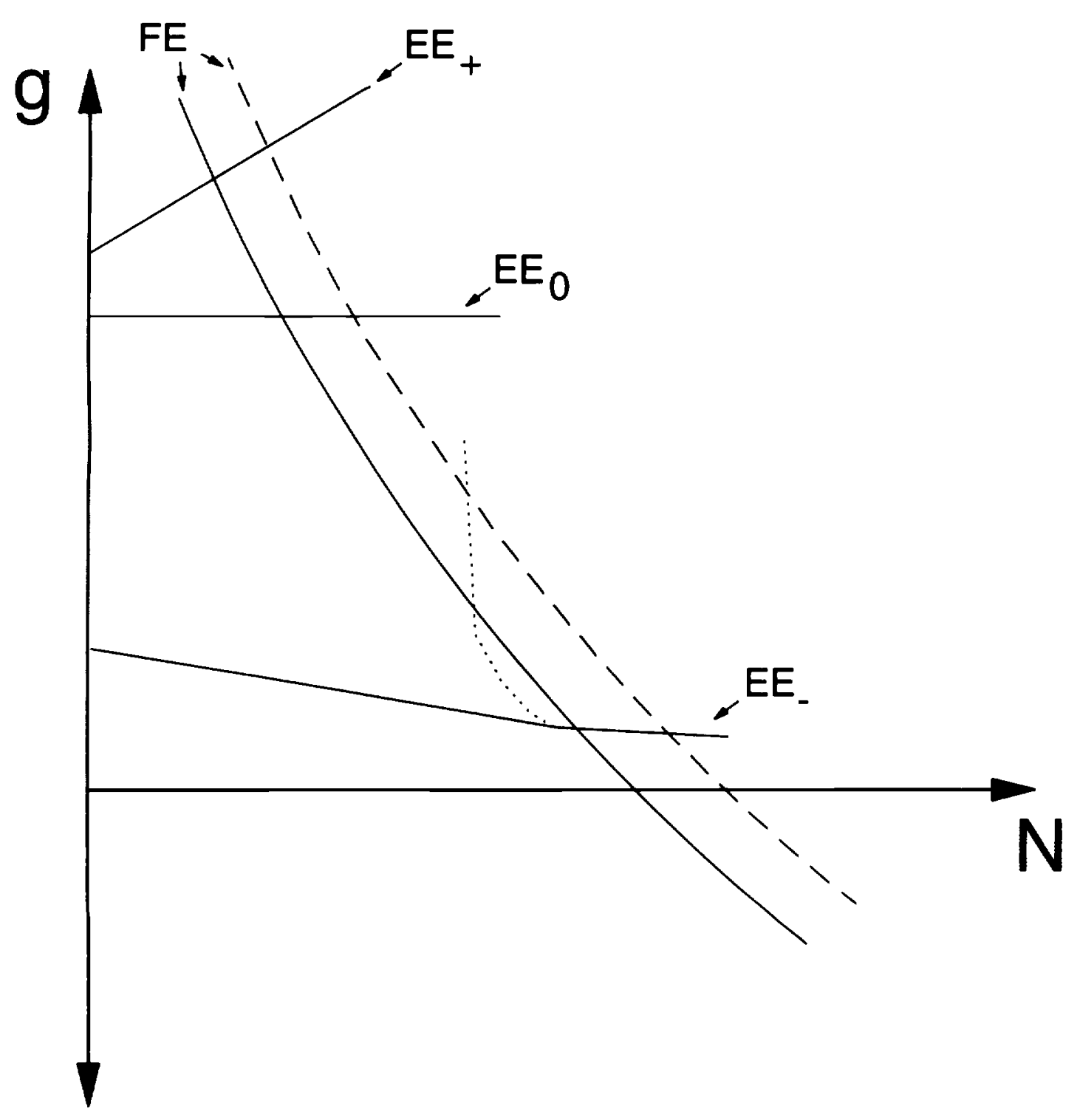


discounted profits, which, in the absence of a marginal cost of production, simply equal total revenue divided by the number of innovators. Like the elasticity relation, this free entry relation includes numerators $\left(\mathrm{p}, \mathrm{L}_{\mathrm{M}}\right)$ and denominators $\left(\mathrm{L}_{1}\right)$ which are all decreasing in $\mathrm{N}$. Consequently, it can be upward or downward sloping in $[\mathrm{N}, \mathrm{g}]$ space. The analysis is somewhat simplified, however, when profits are decomposed into one term reflecting the manufacturing labour force per innovating firm $\left(\frac{L}{N}-f e^{\mu g}\right)$ and another measuring the flow of profits per unit of manufacturing labour $\left(p / L_{1} \lambda\right)$. From the elasticity relation, we know that in equilibrium the latter term, in particular, equals $\frac{1}{\mu_{g}-1}$. Substituting in (44), provides a simpler free entry relation:

(45) $f e^{\mu g}=\mathrm{B} \frac{\frac{L}{N}-f e^{\mu g}}{\mu g-1}$

A more rapid rate of product improvement is associated with higher research costs $\left(f e^{\mu g}\right)$, which raise the innovating firm's investment cost and lower the labour available for manufacturing, while also being associated (in equilibrium) with lowers profits per unit of manufacturing labour $\left(\frac{p}{L_{1} \lambda}=\frac{1}{\mu g-1}\right)$. An increase in $\mathrm{N}$ lowers the quantity of manufacturing labour per firm and, hence, similarly depresses profits. Consequently, this free entry (FE) relation is unambiguously downward sloping in $[\mathrm{N}, \mathrm{g}]$ space, as drawn in figure $\mathrm{I}$.

An increase in $\mathrm{L}$ raises the profitability of innovation and shifts the free entry relation out, while leaving the elasticity relation unchanged. Consequently, when the elasticity of demand is locally increasing (constant) in the number of entrants, as in the case of $\mathrm{EE}_{+}\left(\mathrm{EE}_{0}\right)$, an increase in scale is associated with a rise (no change) in the growth rate. When downward sloping, the EE relation may intersect the FE relation from above or below. When the intersection is from below, as in the case of EE, an increase in scale is associated with an increase in the number of entrants and a fall in the growth rate, as the reduction in the elasticity of demand with respect to product quality reduces the return to product improvement. When the intersection is from above, 
however, as in the case of the dotted line in the figure, an increase in the economy's scale is associated with a decline in the number of entrants and a rise in the growth rate. This equilibrium is easily shown, however, to be dynamically unstable, i.e. for a small pertubation in initial values the economy will diverge from this steady state. ${ }^{20}$ Consequently, focusing on stable equilibria, we may conclude that a rise in the size of the economy will increase the equilibrium number of entrants, with the impact on the economy's growth rate depending upon whether the elasticity of demand with respect to product quality is (locally) increasing, constant, or decreasing in the number of varieties. Examples of economies with positive, zero, and negative scale effects are given by the distance functions $e^{x}, x^{\alpha}(\alpha>1)$, and $\left(4 x^{3}+x^{2}\right) e^{-\frac{1}{x}}$, respectively. Opening an economy to trade or the provision of a proportional R\&D subsidy increase the profitablity of innovative activity and shift out the FE curve, with effects akin to those of a rise in market size.

To conclude, it is interesting to examine the relation between the scale of an economy and the share of its labour force devoted to research. Rearranging (44):

$$
\text { (46) } \frac{N f e^{\mu g}}{L}=\mathrm{B} \frac{p}{L_{1} \lambda}\left[1-\frac{N f e^{\mu g}}{L}\right]
$$

From the above, we see that the share of labour in research is increasing in the flow of profits per unit of manufacturing labour $\left(\frac{p}{L_{1} \lambda}\right)$. Intuitively, this measure, when multiplied by the manufacturing labour per capita, indicates the per capita rents that can be extracted by

\footnotetext{
${ }^{20}$ This is not surprising, since this equilibrium requires that an increase in the profitability of innovative activity be matched by a paradoxical reduction in the number of entrants. Since the EE relation always remains in the positive orthant, while the FE relation does not, it is apparent that any (unstable) intersection from above is always followed by a (stable) intersection from below. Furthermore, the EE relation intersects the $y$ axis at a finite value of $g$. Thus, any intersection from above is preceeded and followed (at lower and higher $\mathrm{N}$, respectively) by intersections from below, and there are always an odd number of intersections. I should note, in addition, that when the EE curve is upward sloping, as in $\mathrm{EE}_{+}$in the figure, the equilibrium may also, on occasion, be unstable (although this is not the case for the example given in the text). An appendix, available upon request from the author, establishes these results.
} 
innovators, which, in equilibrium, must equal per capita expenditure on $R \& D$, or, equivalently, the share of labour in R\&D. Depending upon whether $\frac{p}{L_{1} \lambda}$ is increasing or decreasing in the scale of the economy, the share of labour in research will be similarly increasing or decreasing. Since in equilibrium the flow of profits per unit of manufacturing labour is inversely related to the growth rate of the economy $\left(\frac{p}{L_{1} \lambda}=\frac{1}{\mu g-1}\right)$, we may conclude that the ratio of research to total labour is inversely related to the type of scale effects present in the economy. In this sense, the model provides a nice match with the OECD experience, where increases in scale have been associated with declining growth rates and a rising share of $R \& D$ research in the total labour force.

\section{Socially Optimal Scale Effects}

To conclude the analysis, I examine the degree of socially optimal scale effects in both the Dixit-Stiglitz and Salop versions of the model. Consider the problem facing a social planner who seeks to maximize the utility of the representative consumer in this world. This planner will select a sequence of product qualities, $\lambda(t)$, and number of capital service producers, $N(t)$, so as to: $^{21}$

(47) $\underset{\{\lambda(t) . N(t)\}}{\operatorname{Max}} \sum_{t=0}^{\infty} \mathrm{B}^{\prime} \ln \left\{\frac{L_{M}(t) / L}{L_{1}(t)}\right\}$

where, in both versions of the model, $L_{M}(t)$ is given by:

$$
L_{M}(t)=L-N(t+1) f e^{\mu \lambda(t+1) \lambda(t)}
$$

while $L_{1}(t)$ depends upon the structure of final goods production:

\footnotetext{
${ }^{21}$ It is easily shown that, given a decision to introduce $N(t)$ capital service producers of qualities $\lambda_{i}(t)$ in period $t$, the optimal plan involves giving each producer the same (average) level of product quality and (in the Salop model) spacing the producers evenly along the unit circle. Thus, the decision variables in each period are simply $N(t)$ and $\lambda(t)$.
} 


$$
\begin{aligned}
L_{1}(t) & =c \lambda(t)^{-1} N(t)^{\frac{\alpha-1}{\alpha}} & \text { Dixit-Stiglitz } \\
& =\frac{2 N(t) \int_{0}^{\frac{1}{2 N(t)}} d(x) \mathrm{dx}}{\lambda(t)} & \text { Salop }
\end{aligned}
$$

Using the usual Euler variational arguments (see Stokey and Lucas 1989), one can establish that if a pair $[\lambda(t), N(t)]$ is part of the infinite sequence $\{\lambda(i), N(i)\}_{i=1}^{\infty}$ that maximizes (47), then $[\lambda(t), N(t)]$ must also maximize (47) conditional on the remaining values of the sequence, $\{\lambda(i), N(i)\}_{i=1, \neq \ell}^{\infty}$. Consequently, a necessary condition for a sequence to constitute an optimum is that the derivative with respect to the two choice variables equal zero at each time t:

$$
\begin{aligned}
& \text { (50) } \mathrm{B}^{t-1} \frac{\partial L_{M}(t-1) / \partial N(t)}{L_{M}(t-1)}-\mathrm{B}^{\prime} \frac{\partial L_{1}(t) / \partial N(t)}{L_{1}(t)}=0 \\
& \text { (51) } \quad \mathrm{B}^{t-1} \frac{\partial L_{M}(t-1) / \partial \lambda(t)}{L_{M}(t-1)}-\mathrm{B}^{\prime} \frac{\partial L_{1}(t) / \partial \lambda(t)}{L_{1}(t)}+\mathrm{B}^{\prime} \frac{\partial L_{M}(t) / \partial \lambda(t)}{L_{M}(t)}=0
\end{aligned}
$$

Or, reformulating these equations in terms of elasticities:

$$
\begin{aligned}
& (50)^{\prime} \quad \mathrm{E}_{N(t)}^{L_{M^{(}(t-1)}}=\mathrm{B} \mathrm{E}_{N(t)}^{L_{1}(t)} \\
& (51)^{\prime} \quad \mathrm{E}_{\lambda(t)}^{L_{M^{(}(t-1)}}=\mathrm{B}\left\{\mathrm{E}_{\lambda(t)}^{L_{1}(t)}+\mathrm{E}_{\lambda(t)}^{L_{M}(t)}\right\}
\end{aligned}
$$

where, as earlier above, $E_{j}^{i}$ denotes the elasticity of $i$ with respect to $j$. The left-hand side terms of equations (50)' and (51)' represent the cost of increasing $N(t)$ and $\lambda(t)$, i.e. the reduction in the labour available for manufacturing in period $t-1$. The right-hand side terms of these equations represent the benefits of increasing these variables, which are discounted, since an investment in greater capital variety or product quality taking place in period t-1 yields benefits in period $t$. In the case of an increase in $N(t)$, the benefit is the reduction in the unit labour requirement in period $\mathrm{t}$ brought about by the existence of a closer match between capital varieties and the tasks they perform. In the case of an increase in $\lambda(t)$ there is a two fold benefit, an increase in the 
efficiency of final goods production represented by the reduction in unit labour requirements, and an intertemporal knowledge spillover manifested in an increase in the labour available for period $t$ manufacturing. The latter effect reflects the fact that, since research costs are related to the period by period percentage improvement in product quality, an absolute increase in period $t$ product quality reduces the research labour required to reach any given level of period $t+1$ quality.

To proceed, I evaluate $(50)^{\prime}$ and $(51)^{\prime}$ at the steady state: ${ }^{.22}$

$$
\begin{aligned}
& (50)^{\prime \prime} \frac{N f e^{\mu g}}{L-N f e^{\mu g}}=\mathrm{BE}_{N}^{L_{1}} \\
& (51)^{\prime \prime} \frac{\mu g N f e^{\mu g}}{L-N f e^{\mu g}}=\mathrm{B}\left\{1+\frac{\mu g N f e^{\mu g}}{L-N f e^{\mu g}}\right\}
\end{aligned}
$$

where $\mathrm{g}$ represents the steady state growth of product quality and $\mathrm{N}$ the number of varieties. For the exponential research cost function used in this paper, the steady state elasticity of manufacturing labour with respect to current period product quality $\left(\mathrm{E}_{\lambda_{(t)}}^{L_{M}(t)}=\frac{\mu g N f e^{\mu g}}{L-N f e^{\mu g}}-\right.$ the intertemporal spillover) equals the elasticity of manufacturing labour with respect to next period's product quality ( $\mathrm{E}_{\lambda_{(t)}^{L^{(t-1)}}}^{L}$ - the cost of increasing product quality), and also equals $\mu g$ times the elasticity of manufacturing labour with respect to next period's variety $\left(\mathrm{E}_{N(t)}^{L_{M}(t-1)}-\right.$ the opportunity cost of increasing product variety). In both versions of the model the elasticity of the unit labour requirement is simply 1 , as seen in the first term on the right-hand side of $(51)^{\prime \prime}$. $\mathrm{E}_{N}^{L_{1}}$, however, varies with the type of preferences used in the model. Rearranging $(51)^{\prime \prime}$ and making use of it to substitute in (50)" provides the following simplified relations:

\footnotetext{
${ }^{22}$ Non-steady state values for $\lambda(t)$ and $N(t)$ lead to divergent paths. Since, from the point of view of the social planner, there are no meaningful state variables at time 0 (the levels of $\lambda(0)$ and $N(0)$ influence the initial level of utility but have no intertemporal impact), the socially optimal plan involves an immediate movement to a steady state path.
} 


$$
\begin{aligned}
& \left(\frac{1}{\mu g}\right)\left(\frac{\mathrm{B}}{1-\mathrm{B}}\right)=\mathrm{BE}_{N}^{L_{1}} \\
& (1-\mathrm{B})\left\{\frac{\mu g N f e^{\mu g}}{L-N f e^{\mu g}}\right\}=\mathrm{B}
\end{aligned}
$$

Examples of equations (52) and (53) are drawn in figure II. From (53), the QQ relation equates the marginal cost of increased product quality (net of the intertemporal spillover) to its discounted marginal benefit. The marginal cost, the elasticity of manufacturing labour with respect to product quality, on the left-hand side of the equation, is increasing in both $\mathbf{N}$ and $\mathrm{g}$, as each incremental increase in the research effort, drawn from a fixed pool of labour, requires proportionally larger and larger sacrifices in current manufacturing output. The marginal benefit, the elasticity of output with respect to product quality, on the right-hand side of the equation, is a constant, independent of $\mathrm{N}$ and $\mathrm{g}$. Consequently, the $\mathrm{QQ}$ relation is unambiguously downward sloping in $[\mathrm{N}, \mathrm{g}]$ space. From (52), the QN relation equates the marginal cost of product variety to its benefit. As the equation shows, conditional upon the selection of optimal quality, ${ }^{23}$ the marginal cost of increased variety is inversely related to the economy's growth rate. The benefit of increased variety is, of course, the elasticity of the unit labour requirement with respect to that variable. In the case of the Dixit-Stiglitz version of the model, as well as for the Salop version with $d(x)=x^{\alpha}$, this elasticity is independent of the number of entrants. In those cases the QN relation is a horizontal curve, as in the case of $\mathrm{QN}_{0}$ drawn in the figure. For more general functional forms in the Salop model, this curve may be upward sloping (e.g. for $d(x)=e^{x}$ ) or downward sloping (e.g. for $\left.d(x)=\left(4 x^{3}+x^{2}\right) e^{-\frac{1}{x}}\right)$ and, of course, need not be monotonic. Some examples are drawn in the figure.

An increase in $\mathrm{L}$ shifts the QQ curve out, while leaving the $\mathrm{QN}$ relation unchanged.

\footnotetext{
${ }^{23}$ Recall that (52) is derived by substitution using $(51) "$.
} 
Figure II: Socially Optimal Scale Effects

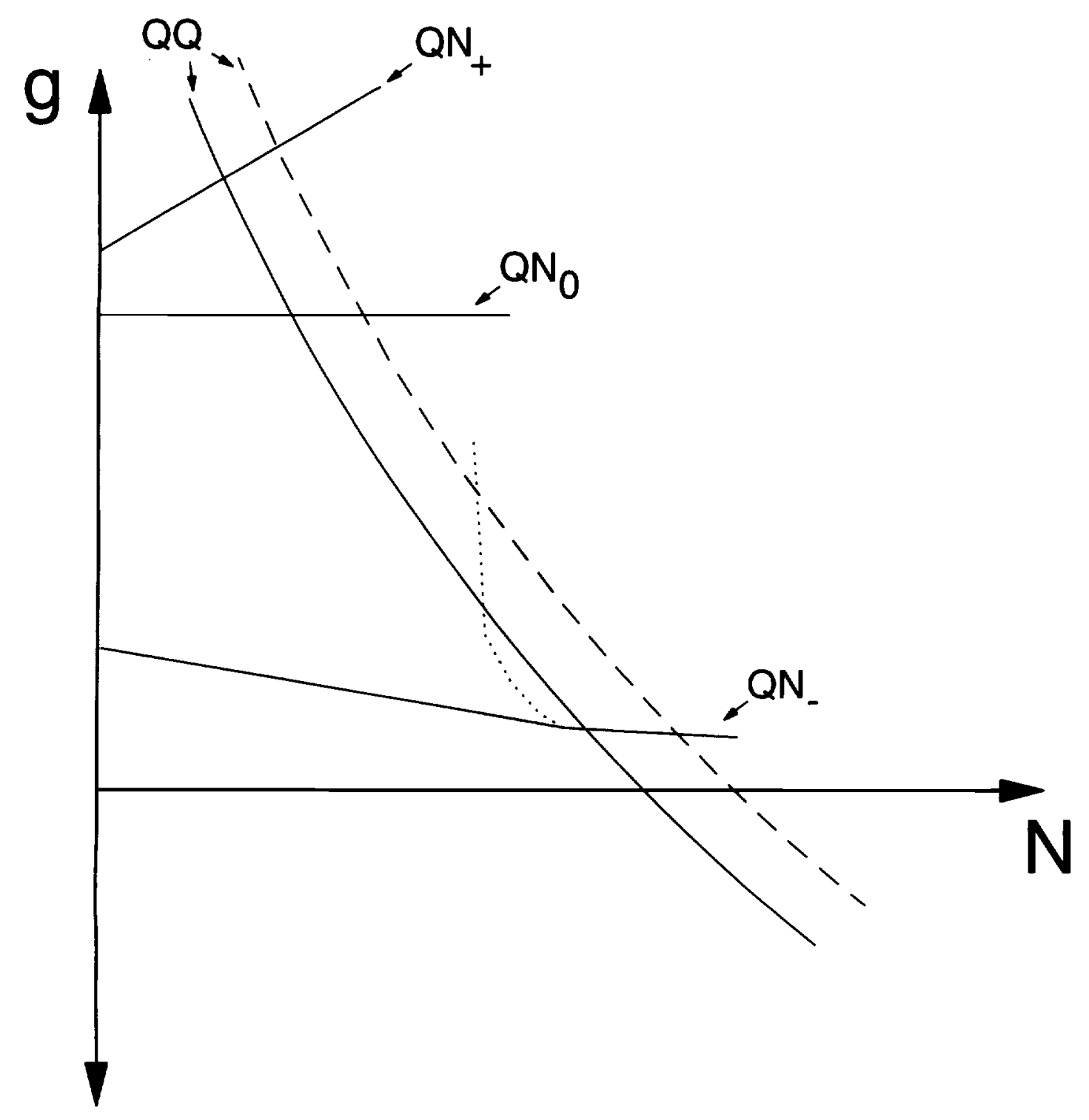


Consequently, when the elasticity of the unit labour requirement with respect to $\mathrm{N}$ is decreasing in (independent of) the number of varieties, as in the case of the curve $\mathrm{QN}_{+}\left(\mathrm{QN}_{0}\right)$ drawn in the figure, the social optimum has positive (zero) scale effects. When the $\mathrm{QN}$ relation is downward sloping, as in the case of QN. in the figure, it may cut the QQ curve from above or below. Any intersection from above, however, must be preceeded and followed by intersections from below ${ }^{24}$ and it can be shown that the discounted value of utility is always higher at these intersections. ${ }^{25}$ Thus, we may conclude that when the QN curve is downward sloping, i.e. when the elasticity of the unit labour requirement is increasing in the number of varieties, the social optimum exhibits negative scale effects.

The intuition behind the type of scale effects exhibited by the social optimum is fairly simple. When the QN curve is upward sloping, the elasticity of the unit labour requirement with respect to the number of capital varieties is decreasing in the total number of entrants. In the

${ }^{24}$ On the one hand, the $\mathrm{QN}$ curve intersects the $\mathrm{y}$ axis at a finite value of $\mathrm{g}$ while the $\mathrm{QQ}$ curve asymptotes to $[0, \infty)$. On the other hand, the $Q Q$ curve crosses the $x$ axis at $N=L / f$ while the $\mathrm{QN}$ curve remains in the strictly positive orthant.

${ }^{25}$ In other words, while an intersection from above may constitute a local maximum (it frequently, although not always, violates second order conditions), it cannot be a global maximum. Intuitively, for a given value of $\mathrm{N}$, the $\mathrm{QN}$ relation maps out (along the $\mathrm{g}$ axis) the inverse of the marginal value of increased variety. This value is, however, conditional upon the QQ relation holding (recall the substitution using (51)"). The QQ relation gives, for each value of $\mathrm{N}$, the actual level of $\mathrm{g}$, that is the actual inverse of the marginal cost of additional variety. Consequently, when the QQ relation lies above (below) the QN relation the marginal cost is below (above) the marginal benefit and total utility rises (falls) with a rise in variety. It follows that any intersection from above is preceeded and followed by intersections from below at which the total value of utility is greater (an appendix, available upon request from the author, provides a formal proof of this argument). As regards multiple intersections from below (separated by sub-optimal intersections from above), it is not possible to establish generally which local optimum consitutes the global social optimum. In this case, the global optimum can only be determined by comparing the total discounted value of consumer utility at each local maximum using particular functional forms (equivalently, one has to integrate a weighted measure of the area between the two curves). The result stated in the text nevertheless holds: if the QN relation is downward sloping, the social optimum (at one of the intersections from above) exhibits negative scale effects. With non-monotonic $\mathrm{QN}$, of course, the type of scale effects present in the economy will vary with the level of $L$. 
face of this form of diminishing returns, the social planner, when endowed with a larger resource base, devotes resources to both increasing the level of utility $(\mathrm{N})$ and its growth rate $(\mathrm{g})$. When the QN curve is horizontal, the social planner faces a constant to returns to scale investment technology, i.e. the elasticity of the unit labour requirement with respect to capital varieties is independent of the number of entrants and the social planner can always achieve the same proportional increase in the level of utility for the same proportional increase in investment. Finally, when the QN curve is downward sloping, the social planner faces an increasing returns to scale investment technology, one in which the elasticity of the unit labour requirement rises with the number of entrants. In this case, as the resource base of the economy expands the social planner exploits these increasing returns to a greater degree, increasing the level of utility at the expense of its growth rate.

As can be seen from the analysis in figure II, for Dixit-Stiglitz preferences, and for the distance functions $e^{x}, x^{\alpha}$, and $\left(4 x^{3}+x^{2}\right) e^{-\frac{1}{x}}$ in the Salop model, the type of scale effects present in the market equilibrium (positive, negative or zero) correspond to those present in the social optimum. This is not, however, generally true. Let $K(N)$ equal the inverse of the elasticity of the unit labour requirement with respect to the number of varieties. ${ }^{26}$ The type of scale effects present in the social optimum depend upon the sign of the derivative of $K(N)$ which, for example in the Salop model, equals:

$$
{ }^{26} \text { I.e. } K(N)=\frac{\int_{0}^{\frac{1}{2 N}} d(x) d x}{\frac{1}{2 N} d\left(\frac{1}{2 N}\right)-\int_{0}^{\frac{1}{2 N}} d(x) d x} .
$$




$$
K^{\prime}(N)=\frac{\int_{N}^{\infty} \frac{d\left(\frac{1}{2 N}\right)^{2} H^{\prime}(N)}{4 N^{3}} \mathrm{dN}}{2 N^{2}\left\{\frac{1}{2 N} d\left(\frac{1}{2 N}\right)-\int_{0}^{\frac{1}{2 N}} d(x) \mathrm{dx}\right\}^{2}}
$$

where $H(N)=\frac{L_{1} \lambda}{p}$, as given by equation (43) earlier. The type of scale effects present in the free market equilibrium depend upon the sign of $H^{\prime}(N)$. Consequently, when $H(N)$ is monotonic we may conclude that the social optimum exhibits the same type of scale effects as are present in the market equilibrium. When $\mathrm{H}(\mathrm{N})$ is not monotonic, however, the two types of equilibria may exhibit different types of scale effects. This is not surprising since the determination of the social optimum and market equilibrium, while related by their common dependence on the functional form of $\mathrm{d}(\cdot)$, involve the maximization of decidedly different objective functions.

To conclude, we consider the relation between the socially optimal degree of variety and rate of growth and the levels of these variables achieved in the free market equilibrium focusing, for reasons of brevity, on the case of Dixit-Stiglitz preferences. In each case, the equilibrium degree of variety and growth is determined by two equations, which might usefully be compared. In the social optimum the optimal degree of variety, for a given a research cost, can be thought of as being determined by the first order condition with respect to $\mathrm{N}$ (equation (50)' earlier), relating the elasticity of manufacturing labour with respect to variety to the elasticity of the unit labour requirement with respect to that variable. For Dixit-Stiglitz preferences, this condition reduces to:

$$
\frac{N_{s o} f e^{\mu_{s o}}}{L-N_{s o} f e^{\mu_{s o}}}=\mathrm{B} \frac{1-\alpha}{\alpha}
$$

In the market equilibrium, for given pricing and rates of product quality improvement, the number of varieties is determined by the free entry condition (equation (9)), which is given by: 
(56) $f e^{\mu g_{M E}}=\mathrm{B} \frac{\left(\frac{1-\alpha}{\alpha}\right)\left(L-N_{M E} f e^{\mu g_{M E}}\right)}{N_{M E}}$

Equations (55) and (56) are clearly identical, and are drawn as such in figure III. The equilibrium product quality improvement selected by free market firms is given by the first order condition (8) earlier. Dividing this by the free entry condition, i.e. conditioning upon the determination of the equilibrium degree of variety, this reduces to the elasticity relation (11), whose functional expression is:

(57) $\mu g_{M E}=\frac{\alpha}{1-\alpha}$

The equivalent relation for the social optimum is given by the first order condition with respect to product quality, equation $(51)^{\prime}$, which, dividing by the first order condition with respect to variety, i.e. conditioning upon the determination of the equilibrium degree of variety, reduces to:

(58) $(1-\mathrm{B}) \mu g_{s o}=\frac{\alpha}{1-\alpha}$

(57) and (58) are horizontal lines, with (58) lying above (57), as drawn in figure III.

As is well known (see Aghion \& Howitt 1992, Grossman and Helpman 1991a, and Tirole 1988 ) in models of endogenous innovation the socially optimal level of innovation may generally be greater or less than that achieved in the market equilibrium. In innovating, private firms both increase consumer surplus and steal the rents of other producers. Failure to capture all of the consumer surplus generated by their actions, as well as failure to internalize the intertemporal spillover of knowledge creation, leads to insufficient private innovation. The ability of firms to steal the rents of other producers, however, leads to (socially) excessive innovation. It is also well known that with Dixit-Stiglitz preferences the consumer surplus and rent stealing effects exactly cancel leading, in the absence of an intertemporal spillover, to an 
Figure III: Variety and Growth

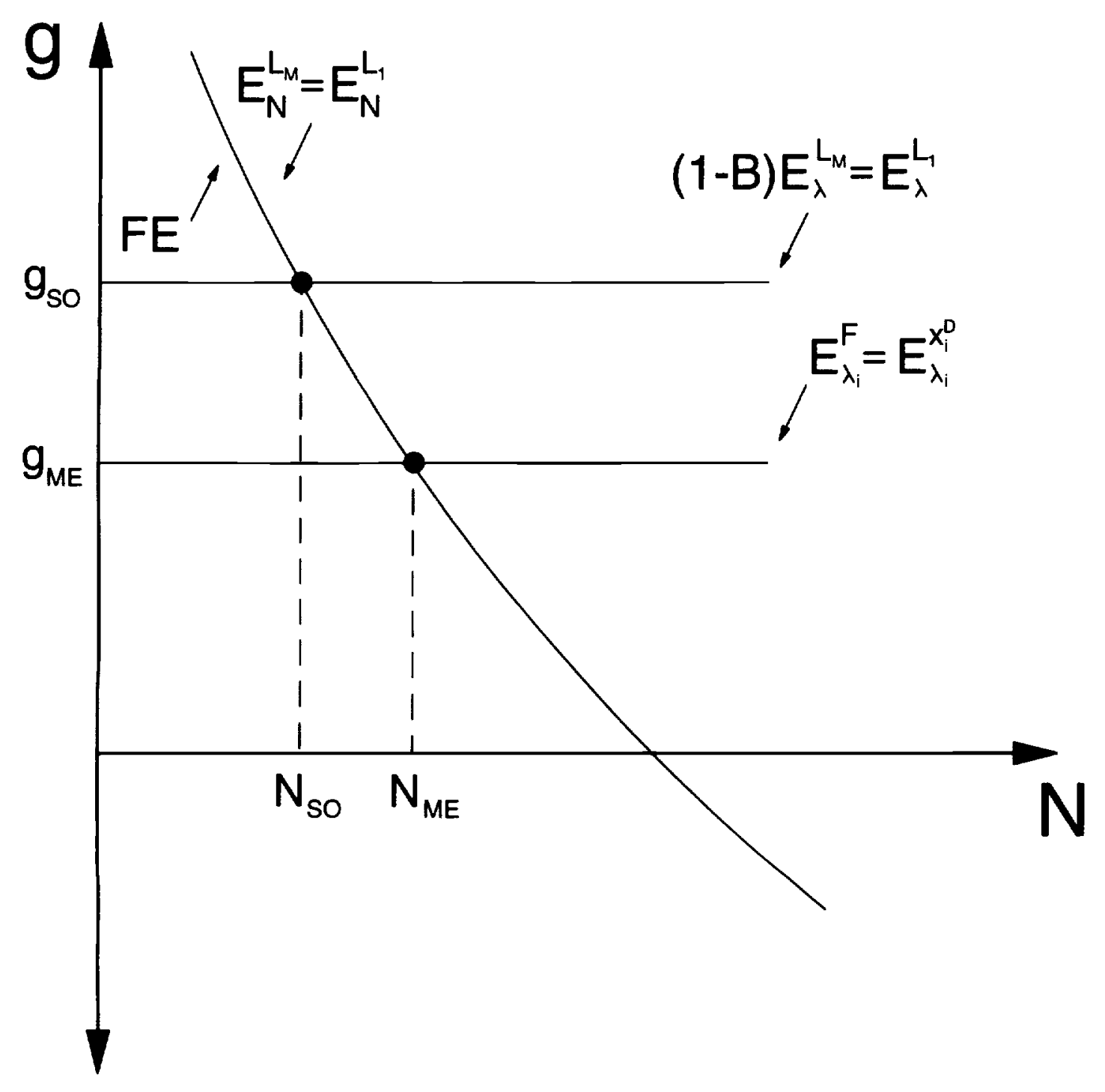


exact equality between the degree of innovation present in the social optimum and the free market equilibrium. ${ }^{27}$

In the model of this paper there is no intertemporal spillover on the horizontal dimension. Consequently, on the horizontal dimension, i.e. taking the degree of product quality improvement as given, rates of innovation in the social optimum and market equilibrium coincide, as indicated by the equality of equations (55) and (56). On the vertical dimension, however, there is an intertemporal spillover. Thus, for a given degree of product variety (i.e. moving up from the $\mathrm{x}$ axis in figure III) the socially optimal degree of innovation is greater than that achieved in the market equilibrium. ${ }^{28}$ Combining both relations, we see that in equilibrium the socially optimal degree of variety lies below that achieved by the free market, while the socially optimal growth rate exceeds its market counterpart, with the the overall resources devoted to innovation being equal in both equilibria. The social optimum can be achieved, in a market setting, by combining a graduated R\&D subsidy (one which is rising in the degree of product qualty improvement) with an overall proportional tax on R\&D activity. ${ }^{29}$

${ }^{27}$ See Grossman and Helpman [1991a, pp. 82-83]. This result is conditional upon the lack of a perfectly competitive sector in the economy. When such a sector exists, the socially optimal plan involves removing the monopoly pricing distortion and expanding the total output of the (formerly) monopolistic competitive industry (see Dixit-Stiglitz 1977). In a model of innovation, this requires increasing innovative activity (in that sector) above the levels achieved by the market equilibrium.

${ }^{28}$ If the intertemporal spillover were absent from the model, the -B term would disappear from the left-hand side of (58) and the socially optimal and market degree of innovation would coincide along the vertical dimension as well.

${ }^{29}$ Specifically, let $\tau$ be the proportion of the fixed cost of innovation (the left-hand side of (56)) borne by innovators. The socially optimal plan involves making:

$$
\tau=e^{\mu \mathrm{B}\left(\frac{\alpha}{(1-\mathrm{B}) \mu(1-\alpha)}-\frac{\lambda_{i}(t)}{\lambda(1-1)}\right)}
$$

The first term within the parentheses represents a proportional tax, and the second term a graduated subsidy. The proportional tax is necessary to offset the impact of the graduated subsidy on the position of the free entry relation. In general, as the social optimum involves two 


\section{Summary and Conclusion}

This paper modifies conventional "quality ladders" models of product improvement to allow for the endogenous determination of the degree of product variety. This apparently minor theoretical modification eliminates one of the most consistent predictions of models of endogenous innovation: that larger economies should grow faster. If new technologies are non-rival, increases in market size will raise the profitability of inventive activity. In standard models of endogenous innovation the only means whereby increased rents can be dissipated is through faster rates of innovation, which destroy the rents of past innovators more rapidly. The model of this paper adds an additional degree of freedom, allowing rents to be dissipated by either increased quality improvement or increased entry. It is immediately apparent that circumstances could arise in which increased entry dissipates all increases in rents, i.e. in which the rate of product quality improvement is invariant with respect to the scale of the economy. In this case, changes in the profitability of innovation, brought about by changes in the scale of an economy, by the provision of proportional subsidies to $R \& D$, or by the opening of an economy to trade, will have important effects on the level of consumer utility, without, however, changing its growth rate. This zero scale effects outcome is, however, by no means an extreme result. As this paper has shown, when product quality and variety are jointly determined, changes in the total pool of rents can lead to any number of outcomes, including cases in which increased entry leads to a decline in the long run growth rate, as a rise in the number of available varieties lowers the return to product improvement.

objectives (variety and growth) as determined by two free market firm optimality conditions (free entry and the elasticity relation), achievement of the social optimum requires two instruments, a proportional R\&D tax/subsidy and a graduated (quality dependent) R\&D tax/subsidy. I should note that, as there are no perfectly competitive sectors in the economy, the monopoly pricing distortion is not a relevant consideration in the determination of the social optimum. 
In the postwar OECD economy most of the variables identified by growth theorists as benefiting growth have trended up. Educational levels have risen, trade barriers have been eliminated, markets have grown and, in precisely the theoretically predicted fashion, the total expenditure and effort devoted to R\&D has risen dramatically. This increase in research effort has not, however, manifested itself in higher growth rates. While it is possible to explain this puzzle in terms of measurement problems, either of the total R\&D effort or of the quality and variety adjusted growth rate, it is also possible to seek a theoretical explanation. This paper brings the dynamic intertemporal models of endogenous growth back to their roots in static general equilibrium models of increasing returns (e.g. Krugman 1979), which emphasized the important impact of scale and trade on the level of utility, as determined by the variety of products available. The size of a market and the level of $R \& D$ expenditure might have as much, if not more, to do with the level of utility, as with its growth rate. 


\section{Bibliography}

Aghion, Philippe and Howitt, Peter. "A Model of Growth through Creative Destruction." National Bureau of Economic Research, Working Paper \#3223.

and _ "A Model of Growth through Creative Destruction." Econometrica 60, No. 2 (March 1992): 323-351.

Backus, David K., Kehoe, Patrick J., and Kehoe, Timothy J. "In Search of Scale Effects in Trade and Growth." Journal of Economic Theory 58 (1992): 377-409.

Dixit, Avinash K. and Stiglitz, Joseph E. "Monopolistic Competition and Optimum Product Diversity." American Economic Review 67, No. 3 (June 1977): 297-308.

Economides, Nicholas. "Symmetric Equilibrium Existence and Optimality in Differentiated Product Markets." Journal of Economic Theory 47 (1989): 178-194.

Evenson, Robert E. "International Invention: Implications for Technology Market Analysis." In Zvi Griliches, ed., R\&D, Patents and Productivity, Chicago: University of Chicago Press, 1984, pp. 89-123.

Gilfillan, S.C. Inventing the Ship. Chicago: Follett Publishing Company, 1935a.

The Sociology of Invention. Chicago: Follett Publishing Company, $1935 \mathrm{~b}$.

Griliches, Zvi. "Patents: Recent Trends and Puzzles." Brookings Papers on Economic Activity, Microeconomics, 1989: 291-319.

Grossman, Gene M. and Helpman, Elhanan. "Product Development and International Trade." Journal of Political Economy 97, No. 6 (December 1989): 1261-1283.

and $\ldots$ Innovation and Growth in the Global Economy. Cambridge: The MIT Press, 1991a.

and __ "Quality Ladders and Product Cycles." Quarterly Journal of Economics 106 (May 1991b): 557-586.

and _. "Quality Ladders in the Theory of Growth." Review of Economic Studies 58 (January 1991c): 43-61.

Jones, Charles I. "Empirical Evidence on R\&D Based Models of Economic Growth." Manuscript. Department of Economics, Stanford University, 1994.

"R\&D Based Models of Economic Growth." Forthcoming. Journal of Political Economy (August 1995a).

"Time Series Tests of Endogenous Growth Models." Quarterly Journal of Economics 110 (May 1995b): 495-525. 
Jones, Larry E. and Manuelli, Rodolfo. "A Convex Model of Equilibrium Growth." Journal of Political Economy 98 (1990): 1008-1038.

Judd, Kenneth L. "On the Performance of Patents." Econometrica Vol. 53, No. 3 (May 1985): 567-585.

Kortum, Samuel. "Equilibrium R\&D and the Patent-R\&D Ratio: U.S. Evidence." American Economic Review 83, No. 2 (May 1993): 450-457.

Kremer, Michael. "Population Growth and Technological Change: One Million B.C. to 1990." Quarterly Journal of Economics 106, No. 3 (August 1993): 681-716.

Krugman, Paul. "Increasing Returns, Monopolistic Competition and International Trade." Journal of International Economics 9, No. 4 (November 1979): 469-479.

Lucas, Robert E., Jr. "On the Mechanics of Economic Development." Journal of Monetary Economics 22 (July 1988): 3-42.

Matsuyama, Kiminori. "Agricultural Productivity, Comparative Advantage, and Economic Growth." Journal of Economic Theory 58, No. 2 (December 1992): 317-334.

Rebelo, Sergio. "Long Run Policy Analysis and Long Run Growth." Journal of Political Economy 99 (1991): 500-521.

Romer, Paul M. "Increasing Returns, Specialization, and External Economies: Growth as Described by Allyn Young." Working paper, revised 1988.

. "Are Nonconvexities Important for Understanding Growth?" American Economic Review 80, No. 2 (May 1990a): 97-103.

. "Endogenous Technological Change." Journal of Political Economy 98, no. 5, pt. 2 (October 1990b): S71-S102.

Salop, Steven C. "Monopolistic Competition with Outside Goods." Bell Journal of Economics 10, No. 1 (Spring 1979): 141-156.

Stokey, Nancy L. and Lucas, Robert E., Jr. Recursive Methods in Economic Dynamics. Cambridge: Harvard University Press, 1989.

Tirole, Jean. The Theory of Industrial Organization. Cambridge: The MIT Press, 1988.

Young, Alwyn. "Learning by Doing and the Dynamic Effects of International Trade." Quarterly Journal of Economics 106 (May 1991): 369-405.

. "Substitution and Complementarity in Endogenous Innovation." Quarterly Journal of Economics 108 (August 1993): 775-807. 